\title{
Aspirin use and survival after the diagnosis of breast cancer: a population-based cohort study
}

\author{
D M Fraser ${ }^{1}$, F M Sullivan², A M Thompson ${ }^{3}$ and C McCowan ${ }^{\star} 4$
}

${ }^{1}$ Division of Population Health Sciences, Medical Research Institute, University of Dundee, Dundee DD2 4BF, UK; ${ }^{2}$ UTOPIAN, University of Toronto, North York General Hospital, 4001 Leslie Street, Room GS-70, Toronto, ON M2K 1E1, Canada; ${ }^{3}$ Department of Surgical Oncology, MD Anderson Cancer Center, 1515 Holcombe Boulevard, Houston TX 77030, USA and ${ }^{4}$ Robertson Centre for Biostatistics, Institute of Health and Wellbeing, College of Medical, Veterinary and Life Sciences, University of Glasgow, Boyd Orr Building, Level 11, Glasgow G12 800, UK

Background: Aspirin use has been associated with a reduced cancer incidence and fewer deaths from cancer. This study examined whether women with breast cancer prescribed aspirin postdiagnosis had improved survival.

Methods: An observational, population cohort study was undertaken using data linkage of cancer registry, dispensed prescriptions and death records in Tayside, Scotland. All community prescriptions for aspirin in women with breast cancer were extracted and use postdiagnosis for each individual examined using Cox's proportional hazard models. The main outcome measures were all-cause mortality and breast cancer-specific mortality.

Results: Four thousand six hundred and twenty-seven patients diagnosed with breast cancer between 1 January 1998 and 31 December 2008 were followed up until 28 February 2010. Median age at diagnosis was 62 (IQR 52-74). One thousand eight hundred and two (39\%) deaths were recorded, with 815 (18\%) attributed to breast cancer. One thousand and thirty-five (22\%) patients were prescribed aspirin postdiagnosis. Such aspirin use was associated with lower risk of all-cause mortality $(H R=0.53$, $95 \% \mathrm{Cl}=0.45-0.63, P<0.001)$ and breast cancer-specific mortality $(\mathrm{HR}=0.42,95 \% \mathrm{Cl}=0.31-0.55, P<0.001)$ after adjusting for age, socioeconomic status, TNM stage, tumour grade, oestrogen receptor status, surgery, radiotherapy, chemotherapy, adjuvant endocrine therapy and aspirin use prediagnosis.

Conclusions: Aspirin use postdiagnosis of breast cancer may reduce both all-cause and breast cancer-specific mortality. Further investigation seeking a causal relationship and which subgroups of patients benefit most await ongoing randomised controlled trials.

Breast cancer is the most common malignancy in the United Kingdom, with over 40000 women diagnosed in 2008 (Maddams et al, 2009). The molecular events leading to the initiation and progression of breast cancer are not completely understood; however, tissue enzymes such as aromatases and prostaglandins may have a role in the development of the disease.(Kulendran et al, 2009; Hoellen et al, 2011)

Aspirin is a common non-steroidal anti-inflammatory drug (NSAID) often used for analgesia or at low dosage as an antiplatelet agent for the prevention of myocardial infarction and stroke.
Aspirin acts by irreversibly inhibiting cyclooxygenase (PTGS, previously COX-1) and modifies the activity of PTGS-2 required for the synthesis of prostaglandins. Other NSAIDs, such as ibuprofen, reversibly inhibit cyclooxygenase. Non-steroidal anti-inflammatory drugs, particularly aspirin, may have chemopreventive or even therapeutic properties for several common types of cancer (Gupta and DuBois, 2001; Rostom et al, 2007; Takkouche et al, 2008).

Several case-control studies have shown a significant reduction in the risk of breast cancer with NSAID and aspirin use (Harris et al, 2006; Kirsh et al, 2007). However, prospective 
studies have given mixed results; aspirin has been shown to have no association (Gill et al, 2007; Jacobs et al, 2007), a decreased risk (Schreinemachers and Everson, 1994; Harris et al, 2003) or an increased risk (Friis et al, 2008); non-aspirin NSAIDS have been associated with a reduced risk (Schreinemachers and Everson, 1994; Harris et al, 2003; Gill et al, 2007).

Aspirin, but not NSAIDs, may interact with other cellular processes, independent of aromatase and oestrogen expression (Bardia et al, 2011). An indirect effect of aspirin on mammary serpin (maspin) has been implicated in the prevention and control of breast cancer (Zou et al, 1994) and in an animal model by restoring nitrous oxide synthesis, increasing maspin production (Bhattacharyya et al, 2010). Overexpression of PTGS-2 in tumours has also been linked to promoting angiogenesis and inhibiting apoptosis (Sheng et al, 1998; Rozic et al, 2001), further implicating that aspirin could prevent growth, metastasis and recurrence.

In the therapeutic setting, a significant reduction in relative risk by taking aspirin for 2 or more days per week was demonstrated both for breast cancer metastasis and breast cancer mortality (Holmes et al, 2010). In a questionnaire-based cohort study of 41000 postmenopausal women (aged 55-69 years), aspirin was associated with a reduction in all-cause mortality and breast cancer mortality (Blair et al, 2007).

The aim of this study was to examine if aspirin use in a population-based cohort of women with breast cancer postdiagnosis was associated with all-cause mortality or breast cancer-specific mortality.

\section{MATERIALS AND METHODS}

The Health Informatics Centre (HIC) at the University of Dundee holds health-related databases on all 400000 residents of the Tayside region, Scotland. All women in Tayside diagnosed with primary invasive breast cancer (ICD10 classifications C50.0-C50.9 or ICD9 classifications 174.0-174.9) between 1 January 1993 and 31 December 2008 and who remained a resident or died in Tayside were identified and studied from the date of diagnosis to either death or the study end date (Makubate et al, 2013). Women with a previous diagnosis of any cancer were excluded. Individual patients were identified and linked to encashed prescribing, cancer registry and audit, death certificate and demographic records. Patients were classed as dying from breast cancer if this was listed on the death certificate as the underlying cause of death. From the encashed prescribing data set from 1 January 1993 to 28 February 2010, aspirin prescriptions were identified and use categorised into: never, prediagnosis only, post breast cancer diagnosis only or pre- plus postdiagnosis groups. Aspirin prescribing postdiagnosis included the prescription coverage, calculated from the number of tablets dispensed and the directions for use, to determine the number of days the prescription would last if the patient took the tablets as directed by the prescribing clinician. Thus, a prescription of 56 tablets with directions of one tablet two times daily would have a coverage of 28 days.

Patient follow-up postdiagnosis was split into periods of aspirin use, or non-use, based on aspirin coverage for each individual until death or the end of follow-up. The total duration of aspirin use was calculated from the date of the first prescription postdiagnosis to the end of coverage of the last prescription. Adherence to aspirin was calculated by dividing the total coverage of the aspirin prescriptions by the total duration of its use (Makubate et al, 2013).

Ethical approval was granted by the Tayside Committee on Medical Research Ethics and the NHS Tayside Caldicott Guardian according to prior arrangements within the HIC (CA/FB HIC Ethics letter dated 3 February 2010).

Statistical analysis. Data were described as the number of subjects (percentages) for categorical variables and mean with standard deviation (s.d.) for continuous variables. Where continuous variables did not follow a normal distribution, they were tested using the Shapiro-Wilks test for skewness, and the median and interquartile range were reported. Likelihood ratios and $\chi^{2}$ tests for trend $\left(\chi^{2}\right.$ trend, degrees of freedom (d.f.), probability $\left.(P)\right)$ were reported for differences in distribution of the population with $n$-ordered categories, otherwise Pearson's $\chi^{2}$ test for differences was used $\left(\chi^{2}\right.$, d.f., $P$ ).

Cox's proportional hazards models were utilised to estimate hazard ratios (HRs) and 95\% confidence intervals (CIs) for each unadjusted and adjusted covariate for cancer diagnosis. Patients were followed up from cancer diagnosis until the date of death or the end of the study. Individual patients who used aspirin postdiagnosis had several linked records each reflecting a period of aspirin use, or no use, which provided continuous follow-up. This marker of aspirin use was included in Cox's proportional hazards model to allow for the effect over time since diagnosis to be accurately examined. The proportional hazards assumption was assessed using trend tests of the Schoenfeld residuals. The multiple regression analysis allowed for age, socioeconomic status (SES), cancer stage and grade at diagnosis, ER status, surgery, radiotherapy, chemotherapy, adjuvant endocrine therapy and aspirin use prediagnosis.

All statistical analyses were performed using Stata version 11 (StataCorp, 2009, Stata Statistical Software: Release 11, College Station TSL, TX, USA).

\section{RESULTS}

There were 4627 women diagnosed with incident breast cancer over 11 years, 1 January 1998 to 31 December 2008 inclusive (see Table 1); follow-up was until death or the end of the study period (28 February 2010). The median age at diagnosis was 62 years (IQR 52-74) and patients were followed up postdiagnosis for 31444 patient years in total, with a median length of follow-up of 5.7 years (IQR 3.0-10.1). One thousand eight hundred and two (39.0\%) patients died during the study period, with 815 (17.6\%) attributed to breast cancer from death certificate records; 3803 $(82 \%)$ patients followed up until death or for a minimum of 5 years postdiagnosis.

There were 682 women (14.7\%) who took aspirin before diagnosis and 1035 (22.4\%) took aspirin postdiagnosis of breast cancer, with a median of 2.4 years use postdiagnosis (IQR 0.7-5.0 years). Calculated adherence to aspirin over the entire period was high, with a median figure of $95.4 \%$ (IQR $81.5-100 \%$ ). The majority, 27484 (99\%), of aspirin prescriptions postdiagnosis were for $75 \mathrm{mg}$ dosage. Other characteristics of patients by aspirin use pre- and postdiagnosis are shown in Table 2. Patients who took aspirin postdiagnosis were older $\left(\chi^{2}\right.$ trend $=400.7$, d.f. $=5$, $P<0.001)$, had higher SES $\left(\chi^{2}\right.$ trend $=50.1$, d.f. $\left.=5, P<0.001\right)$, lower tumour stage $\left(\chi^{2}=13.4\right.$, d.f. $\left.=4, P=0.009\right)$, less metastases $\left(\chi^{2}=9.8\right.$, d.f. $\left.=2, P=0.007\right)$, lower grade tumours $\left(\chi^{2}=9.5\right.$, d.f. $=3, \quad P=0.023)$, were less likely to have radiotherapy $\left(\chi^{2}=27.0, \quad\right.$ d.f. $\left.=2, \quad P<0.001\right)$ or chemotherapy $\left(\chi^{2}=121.2\right.$, d.f. $=2, P<0.001)$ or surgery $\left(\chi^{2}=26.5\right.$, d.f. $\left.=2, P<0.001\right)$ and were more likely to have adjuvant endocrine therapy $\left(\chi^{2}=74.3\right.$, d.f. $=3, P<0.001$ ) (see Table 2).

Using Cox's regression models, an unadjusted model for all-cause mortality in patients taking aspirin after diagnosis was created along with a multiple regression model adjusted for age, SES, tumour characteristics, surgery, radiotherapy, chemotherapy, adjuvant endocrine therapy and aspirin use prediagnosis. The adjusted model showed that aspirin reduced the risk of all-cause mortality $(\mathrm{HR}=0.53,95 \% \mathrm{CI}=0.45-0.63, P<0.001)$ (Table 3$)$. Increasing age, tumour stage, lymph node involvement, metastasis and tumour grade, as well as having chemotherapy were associated 


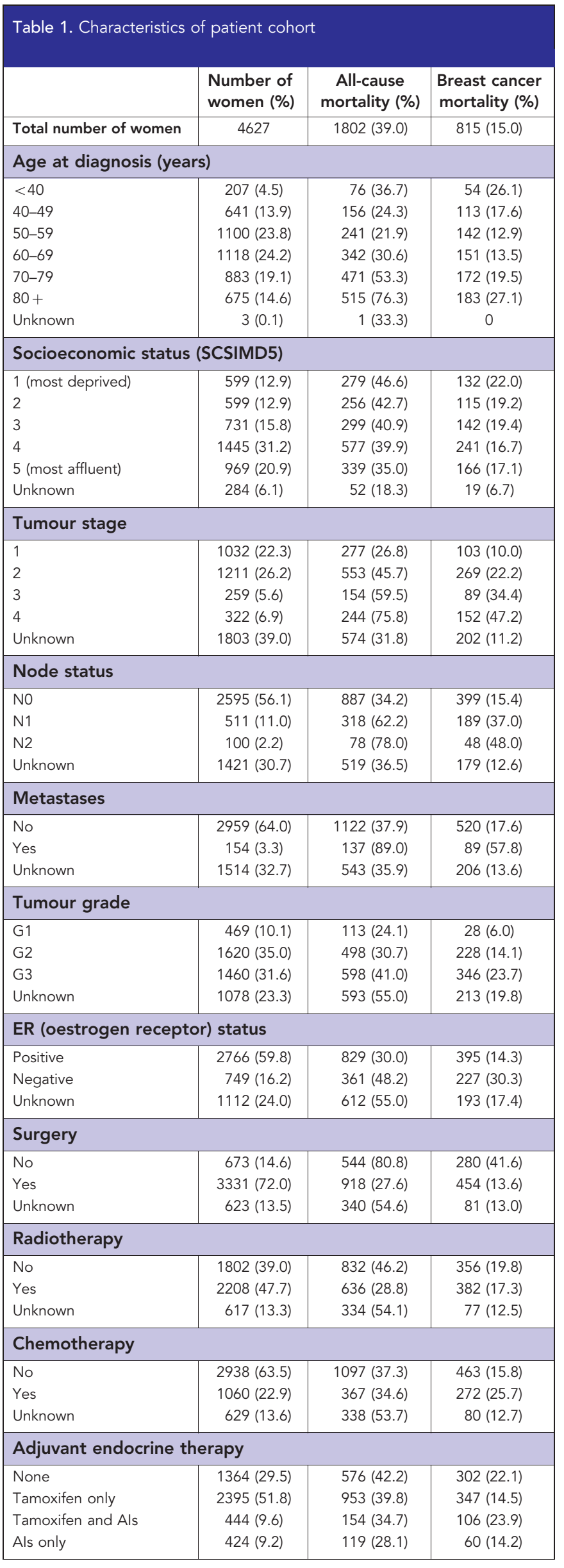

\section{Table 1. (Continued)}

\begin{tabular}{|l|c|r|r|}
\hline \multicolumn{5}{|c|}{$\begin{array}{c}\text { Number of } \\
\text { women (\%) }\end{array}$} & $\begin{array}{r}\text { All-cause } \\
\text { mortality (\%) }\end{array}$ & $\begin{array}{r}\text { Breast cancer } \\
\text { mortality (\%) }\end{array}$ \\
\hline Aspirin use & $3383(73.1)$ & $1225(36.2)$ & $563(16.6)$ \\
Never & $209(4.5)$ & $124(59.3)$ & $68(32.5)$ \\
Prediagnosis only & $473(10.2)$ & $249(52.6)$ & $108(22.8)$ \\
Pre- and postdiagnosis & $562(12.2)$ & $204(36.3)$ & $76(13.5)$ \\
Postdiagnosis only & \multicolumn{4}{|l}{} \\
\hline \multicolumn{4}{|l}{ Abbreviation: Als = aromatase inhibitors. }
\end{tabular}

with an increased risk of all-cause mortality. Increasing social class, having surgery, positive ER status and using adjuvant endocrine therapy were associated with a reduced risk of all-cause mortality (see Supplementary Table 1). However, aspirin use prediagnosis was associated with increased risk of all-cause mortality $(\mathrm{HR}=1.62,95 \% \mathrm{CI}=1.42-1.85, P<0.001)$.

Cox's regression models were also used to report HRs for patients who died from breast cancer. After adjustment, the use of aspirin postdiagnosis was associated with a lower risk of breast cancer mortality $(\mathrm{HR}=0.42,95 \% \mathrm{CI}=0.31-0.55, P<0.001)$. Increasing tumour stage, lymph node involvement and tumour grade, the presence of metastases as well as having chemotherapy were associated with an increased breast cancer mortality. Having surgery or radiotherapy, positive ER status and using adjuvant endocrine therapy reduced the risk of breast cancer mortality. Patients aged 50-59 years were at lower risk than those aged under 40 years, but there was no other effect by age and SES had no effect on risk of breast cancer mortality (see Supplementary Table 2). Again, prediagnosis aspirin use was associated with an increased risk of breast cancer mortality $(\mathrm{HR}=2.10,95 \% \mathrm{CI}=1.73-2.55, P<0.001)$.

To examine the effect of adherence to aspirin on all-cause mortality, patients were classed as having high adherence: $80 \%$ or above (789 patients, $76 \%$ of patients taking aspirin postdiagnosis) or low adherence (246 patients, 24\%) and compared with those patients not taking aspirin. Patients with low adherence had a reduced $\mathrm{HR}$ for death $(\mathrm{HR}=0.56,95 \% \mathrm{CI}=0.45-0.69, P<0.001)$ as did for those with high adherence $(\mathrm{HR}=0.55,95 \% \mathrm{CI}=0.48-0.62$, $P<0.001)$ compared with non-users.

\section{DISCUSSION}

Women who used aspirin following a diagnosis of breast cancer had a reduced risk of all-cause and breast cancer-specific mortality. Advancing age was related to increased risk of death attributable to increased comorbidities, such as cardiovascular disease and stroke. The younger patient age group also fared worse, in keeping with recognised outcome data (Copson et al, 2013).

Patients in the most affluent socioeconomic quintile had a lower risk of all-cause mortality as reported elsewhere in the literature (Fein, 1995; Mackenbach et al, 2003; Marmot, 2003). We found a significantly higher all-cause mortality risk in those patients who took aspirin prediagnosis, suggesting aspirin use as a marker of pre-existing cardiovascular morbidity, which may also mean that they are unable to receive optimal therapy for breast cancer.

The present population-based cohort study confirms the reduction in all-cause mortality with aspirin use (adjusted $\mathrm{HR}=0.53,95 \% \mathrm{CI}=0.36-0.79$ ) (Holmes et al, 2010), and breast cancer-specific mortality (adjusted $\mathrm{HR}=0.53,95 \% \mathrm{CI}=0.30-0.93$ ) (Holmes et al, 2010), or when aspirin was taken postdiagnosis 2-5 days a week (multivariate $\mathrm{RR}=0.40,95 \% \mathrm{CI}=0.24-0.65, P=0.03$ ) (Blair et al, 2007) and 6-7 days a week (multivariate $\mathrm{RR}=0.57$, 95\% CI $=0.39-0.82, P=0.03$ ) (Blair et al, 2007). 


\begin{tabular}{|c|c|c|c|}
\hline & $\begin{array}{c}\text { Post- } \\
\text { diagnosis } \\
\text { non-aspirin } \\
\text { users (\%) }\end{array}$ & $\begin{array}{l}\text { Post- } \\
\text { diagnosis } \\
\text { aspirin } \\
\text { users (\%) }\end{array}$ & $\begin{array}{c}\chi^{2} \text { Test, d.f., } \\
P \text {-value }\end{array}$ \\
\hline Number of women & 3592 & 1035 & \\
\hline \multicolumn{4}{|c|}{ Age at diagnosis (years) } \\
\hline $\begin{array}{l}<40 \\
40-49 \\
50-59 \\
60-69 \\
70-79 \\
80+\end{array}$ & $\begin{array}{l}205(5.7) \\
608(16.9) \\
934(26.0) \\
821(22.9) \\
587(16.4) \\
434(12.1)\end{array}$ & $\begin{array}{c}2(0.2) \\
33(3.2) \\
166(16.0) \\
297(28.7) \\
296(28.6) \\
241(23.3)\end{array}$ & $400.7,5,<0.001$ \\
\hline \multicolumn{4}{|c|}{ Socioeconomic status (SCSIMD5) } \\
\hline $\begin{array}{l}1 \text { (most deprived) } \\
2 \\
3 \\
4 \\
5 \text { (most affluent) } \\
\text { Unknown }\end{array}$ & $\begin{array}{r}450(12.5) \\
474(13.2) \\
527(14.7) \\
1124(31.3) \\
759(21.1) \\
258(7.2)\end{array}$ & $\begin{array}{l}149(14.4) \\
125(12.1) \\
204(19.7) \\
321(31.0) \\
210(20.3) \\
26(2.5)\end{array}$ & $50.1,5,<0.001$ \\
\hline \multicolumn{4}{|l|}{ Tumour stage } \\
\hline $\begin{array}{l}1 \\
2 \\
3 \\
4 \\
\text { Unknown }\end{array}$ & $\begin{array}{l}808(22.5) \\
909(25.3) \\
209(5.8) \\
235(6.5) \\
1431(39.8)\end{array}$ & $\begin{array}{c}224(21.6) \\
302(29.2) \\
50(4.8) \\
87(8.4) \\
372(35.9)\end{array}$ & $13.4,4,0.009$ \\
\hline \multicolumn{4}{|l|}{ Node status } \\
\hline $\begin{array}{l}\text { N0 } \\
\text { N1 } \\
\text { N2 } \\
\text { Unknown }\end{array}$ & $\begin{array}{r}2001(55.7) \\
392(10.9) \\
79(2.2) \\
1120(31.2)\end{array}$ & $\begin{array}{c}594(57.4) \\
119(11.5) \\
21(2.0) \\
301(29.1)\end{array}$ & $1.9,3,0.590$ \\
\hline \multicolumn{4}{|l|}{ Metastases } \\
\hline $\begin{array}{l}\text { No } \\
\text { Yes } \\
\text { Unknown }\end{array}$ & $\begin{array}{c}2270(63.2) \\
134(3.7) \\
1188(33.1)\end{array}$ & $\begin{array}{c}689(66.6) \\
20(1.9) \\
326(31.5)\end{array}$ & $9.8,2,0.007$ \\
\hline \multicolumn{4}{|l|}{ Tumour grade } \\
\hline $\begin{array}{l}\text { G1 } \\
\text { G2 } \\
\text { G3 } \\
\text { Unknown }\end{array}$ & $\begin{array}{c}347(9.7) \\
1235(34.4) \\
1164(32.4) \\
846(23.6)\end{array}$ & $\begin{array}{l}122(11.8) \\
385(37.2) \\
296(28.6) \\
232(22.4)\end{array}$ & $9.5,3,0.023$ \\
\hline \multicolumn{4}{|c|}{ ER (oestrogen receptor) status } \\
\hline $\begin{array}{l}\text { Positive } \\
\text { Negative } \\
\text { Unknown }\end{array}$ & $\begin{array}{r}2139(59.6) \\
595(16.6) \\
858(23.9)\end{array}$ & $\begin{array}{l}627(60.6) \\
154(14.9) \\
254(24.5)\end{array}$ & $1.7,2,0.428$ \\
\hline \multicolumn{4}{|l|}{ Surgery } \\
\hline $\begin{array}{l}\text { No } \\
\text { Yes } \\
\text { Unknown }\end{array}$ & $\begin{array}{r}484(13.5) \\
2651(73.8) \\
457(12.7)\end{array}$ & $\begin{array}{l}189(18.3) \\
680(65.7) \\
166(16.0)\end{array}$ & $26.54,2,<0.001$ \\
\hline \multicolumn{4}{|l|}{ Radiotherapy } \\
\hline $\begin{array}{l}\text { No } \\
\text { Yes } \\
\text { Unknown }\end{array}$ & $\begin{array}{r}1351(37.6) \\
1787(49.8) \\
454(12.6)\end{array}$ & $\begin{array}{l}451(43.6) \\
421(40.7) \\
163(15.8)\end{array}$ & $27.0,2,<0.001$ \\
\hline \multicolumn{4}{|l|}{ Chemotherapy } \\
\hline $\begin{array}{l}\text { No } \\
\text { Yes } \\
\text { Unknown }\end{array}$ & $\begin{array}{r}2174(60.5) \\
954(26.6) \\
464(12.9)\end{array}$ & $\begin{array}{l}764(73.8) \\
106(10.2) \\
165(15.9)\end{array}$ & $121.2,2,<0.001$ \\
\hline \multicolumn{4}{|c|}{ Adjuvant endocrine therapy } \\
\hline $\begin{array}{l}\text { None } \\
\text { Tamoxifen only } \\
\text { Tamoxifen and Als } \\
\text { Als only }\end{array}$ & $\begin{array}{c}1165(32.4) \\
1806(50.3) \\
325(9.1) \\
296(8.2)\end{array}$ & $\begin{array}{l}199(19.2) \\
589(56.9) \\
119(11.5) \\
128(12.4)\end{array}$ & $74.3,3,<0.001$ \\
\hline All-cause mortality & $1349(37.6)$ & $453(43.8)$ & $13.0,1,<0.001$ \\
\hline Breast cancer mortality & $631(17.6)$ & $184(17.8)$ & $0.02,1,0.875$ \\
\hline
\end{tabular}

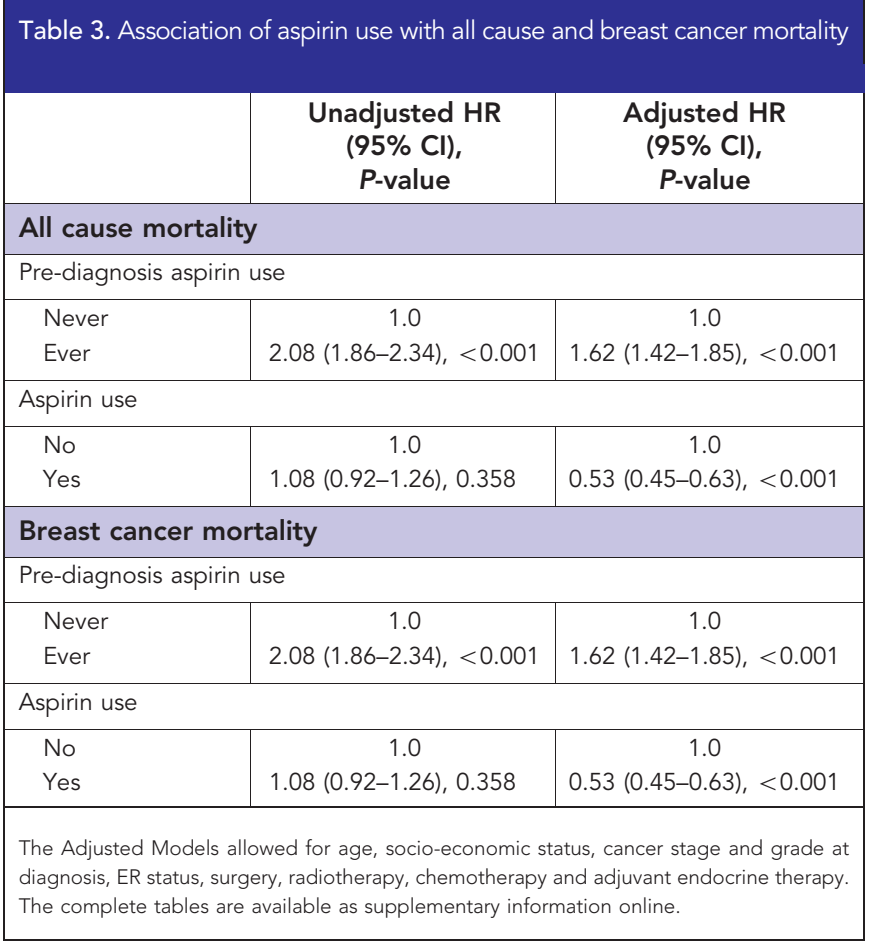

The study looked at all breast cancers diagnosed from an unselected population-based cohort, which included people from all levels of SES and age. The study used dispensed prescribing records from a closed prescribing system where every prescription presented to a pharmacist is subsequently recorded and collated. The prescribing data were then linked to clinical cancer records, cancer registry records and health board population databases to provide the study data set.

Limitations include the lack of over-the-counter medication information for Scotland, although previous work has suggested that long-term use of aspirin is mainly through prescriptions (Morant et al, 2004). We did not have recurrence information on this population as it is not robustly recorded in the routine data sets this work was based upon. Unfortunately, the indication for the aspirin prescription and the actual use (rather than filling the prescription) were not recorded. Most (99\%) of the aspirin used was a low $75 \mathrm{mg}$ dose, so it is unlikely to have been used as analgesia for family members. Similarly, there was no patient data available on smoking status or BMI, useful in establishing a link to increased risk of mortality when aspirin was taken prediagnosis. Long-term low-dose aspirin is associated with an increased risk of peptic ulcer and gastrointestinal bleeding, but we had no information on toxicity and side effects from aspirin use (Yeomans, 2011). It should also be noted that this was an observational study and so there is the potential for the estimated associations to be the result of unmeasured residual confounders.

Clinical implications. Our findings demonstrate a substantial risk reduction in all-cause mortality and breast cancer-specific mortality when aspirin is taken following a diagnosis of breast cancer. Because aspirin use was associated with decreased risk of death from breast cancer, this suggests that aspirin has a direct interaction with the disease, with PTGS-2 inhibition a potential molecular mechanism for aspirin to halt the growth of a tumour and prevent metastasis. It would be very interesting if the survival benefit gained is due to something as nonspecific as PTGS-2 inhibition, thus supporting the current prospective trials of aspirin in breast and other cancer types (Phillips et al, 2013). 
Conclusions. This population-based cohort study suggests that low-dose aspirin prescribed following a diagnosis of breast cancer is associated with a decreased risk of all-cause and breast cancerspecific mortality. Further studies are needed to investigate the exact mechanism of this protective effect. Prospective randomised clinical trials may well define the effectiveness of aspirin for specific patient subgroups in the near future.

\section{ACKNOWLEDGEMENTS}

We thank the staff at the HIC, University of Dundee, for anonymisation, record linkage and other procedural assistance in preparing the data set.

\section{CONFLICT OF INTEREST}

All authors have completed the ICMJE uniform disclosure form at www.icmje.org/coi_disclosure.pdf; none of the authors have financial relationships with any organisations that might have an interest in the submitted work in the previous 3 years and have no other relationships or activities that could appear to have influenced the submitted work.

\section{ETHICS STATEMENT}

All data were fully anonymised and data use were compliant with the HIC research governance process, which are approved by the Tayside Committee on Medical Research Ethics and the Caldicott Guardian.

\section{AUTHOR CONTRIBUTIONS}

$\mathrm{CMcC}$ conceived the study and planned it with FMS and AMT. DF carried out the analysis with support from $\mathrm{CMcC}$. All authors contributed to the writing of the paper. $\mathrm{CMcC}$ is the guarantor.

\section{REFERENCES}

Bardia A, Olson J, Vachon C, Lazovich D, Vierkant R, Wang A, Limburg P, Anderson K, Cerhan J (2011) Effect of aspirin and other NSAIDs on postmenopausal breast cancer incidence by hormone receptor status: results from a prospective cohort study. Breast Cancer Res Treat 126(1): 149-155.

Bhattacharyya M, Girish GV, Ghosh R, Chakraborty S, Sinha AK (2010) Acetyl salicyclic acid (aspirin) improves synthesis of maspin and lowers incidence of metastasis in breast cancer patients. Cancer Sci 101(10): 2105-2109.

Blair CK, Sweeney C, Anderson KE, Folsom AR (2007) NSAID use and survival after breast cancer diagnosis in post-menopausal women. Breast Cancer Res Treat 101(2): 191-197.

Copson E, Eccles B, Maishman T, Gerty S, Stanton L, Cutress RI, Altman DG, Durcan L, Simmonds P, Lawrence G, Jones L, Bliss J, Eccles D, Group PSS (2013) Prospective observational study of breast cancer treatment outcomes for UK women aged 18-40 years at diagnosis: The POSH Study. J Natl Cancer Inst 105: 978-988.

Fein O (1995) The influence of social class on health status. J Gen Intern Med 10(10): 577-586.

Friis S, Thomassen L, Sørensen HT, Tjønneland A, Overvad K, Cronin-Fenton DP, Vogel U, McLaughlin JK, Blot WJ, Olsen JH (2008) Nonsteroidal antiinflammatory drug use and breast cancer risk: a Danish cohort study. Eur J Cancer Prev 172: 88-96.
Gill JK, Maskarinec G, Wilkens LR, Pike MC, Henderson BE, Kolonel LN (2007) Nonsteroidal antiinflammatory drugs and breast cancer risk: the Multiethnic Cohort. Am J Epidemiol 166(10): 1150-1158.

Gupta RA, DuBois RN (2001) Colorectal cancer prevention and treatment by inhibition of cyclooxygenase-2. Nat Rev Cancer 1(1): 11-21.

Harris R, Beebe-Donk J, Alshafie G (2006) Reduction in the risk of human breast cancer by selective cyclooxygenase-2 (COX-2) inhibitors. BMC Cancer 6(1): 27.

Harris RE, Chlebowski RT, Jackson RD, Frid DJ, Ascenseo JL, Anderson G, Loar A, Rodabough RJ, White E, McTiernan A (2003) Breast cancer and nonsteroidal anti-inflammatory drugs: prospective results from the women's health initiative. Cancer Res 63(18): 6096-6101.

Hoellen F, Kelling K, Dittmer C, Diedrich K, Friedrich M, Thill M (2011) Impact of cyclooxygenase-2 in breast cancer. Anticancer Res 31(12): 4359-4367.

Holmes MD, Chen WY, Li L, Hertzmark E, Spiegelman D, Hankinson SE (2010) Aspirin intake and survival after breast cancer. J Clin Oncol 28(9): 1467-1472.

Jacobs EJ, Thun MJ, Bain EB, Rodriguez C, Henley SJ, Calle EE (2007) A large cohort study of long-term daily use of adult-strength aspirin and cancer incidence. J Natl Cancer Inst 99(8): 608-615.

Kirsh VA, Kreiger N, Cotterchio M, Sloan M, Theis B (2007) Nonsteroidal antiinflammatory drug use and breast cancer risk: subgroup findings. Am J Epidemiol 166(6): 709-716.

Kulendran M, Salhab M, Mokbel K (2009) Oestrogen-synthesising enzymes and breast cancer. Anticancer Res 29(4): 1095-1109.

Mackenbach JP, Bos V, Andersen O, Cardano M, Costa G, Harding S, Reid A, Hemström Ö, Valkonen T, Kunst AE (2003) Widening socioeconomic inequalities in mortality in six Western European countries. Int $J$ Epidemiol 32(5): 830-837.

Maddams J, Brewster D, Gavin A, Steward J, Elliott J, Utley M, Moller H (2009) Cancer prevalence in the United Kingdom: estimates for 2008. Br J Cancer 101(3): 541-547.

Makubate B, Donnan PT, Dewar JA, Thompson AM, McCowan C (2013) Cohort study of adherence to adjuvant endocrine therapy, breast cancer recurrence and mortality. Br J Cancer 108(7): 1515-1524.

Marmot MG (2003) Understanding social inequalities in health. Perspect Biol Med 46(3 Suppl): S9-S23.

Morant SV, McMahon AD, Cleland JGF, Davey PG, MacDonald TM (2004) Cardiovascular prophylaxis with aspirin: costs of supply and management of upper gastrointestinal and renal toxicity. Br J Clin Pharmacol 57(2): 188-198.

Phillips I, Langley R, Gilbert D, Ring A (2013) Aspirin as a treatment for cancer. Clin Oncol (R Coll Radiol (Great Britain)) 25(6): 333-335.

Rostom A, Dubé C, Lewin G, Tsertsvadze A, Barrowman N, Code C, Sampson M, Moher D (2007) Nonsteroidal anti-inflammatory drugs and cyclooxygenase-2 inhibitors for primary prevention of colorectal cancer: a systematic review prepared for the U.S. preventive services task force. Ann Intern Med 146(5): 376-389.

Rozic JG, Chakraborty C, Lala PK (2001) Cyclooxygenase inhibitors retard murine mammary tumor progression by reducing tumor cell migration, invasiveness and angiogenesis. Int J Cancer 93(4): 497-506.

Schreinemachers DM, Everson RB (1994) Aspirin use and lung, colon, and breast cancer incidence in a prospective study. Epidemiology 5(2): 138-146.

Sheng H, Shao J, Morrow JD, Beauchamp RD, DuBois RN (1998) Modulation of apoptosis and Bcl-2 expression by prostaglandin E2 in human colon cancer cells. Cancer Res 58(2): 362-366.

Takkouche B, Regueira-Méndez C, Etminan M (2008) Breast cancer and use of nonsteroidal anti-inflammatory drugs: a meta-analysis. J Natl Cancer Inst 100(20): 1439-1447.

Yeomans ND (2011) Aspirin: old drug, new uses and challenges* $J$ Gastroenterol Hepatol 26(3): 426-431.

Zou Z, Anisowicz A, Hendrix M, Thor A, Neveu M, Sheng S, Rafidi K, Seftor E, Sager R (1994) Maspin, a serpin with tumor-suppressing activity in human mammary epithelial cells. Science 263(5146): 526-529.

This work is published under the standard license to publish agreement. After 12 months the work will become freely available and the license terms will switch to a Creative Commons AttributionNonCommercial-Share Alike 3.0 Unported License. 